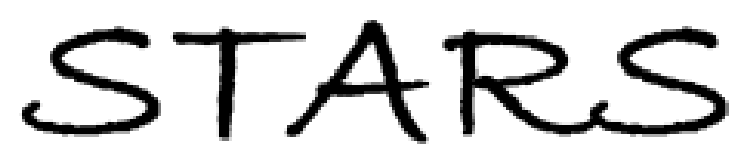

University of Central Florida

STARS

Faculty Scholarship and Creative Works

6-7-2010

\title{
Measuring and Explaining Competitiveness in the Context of Small Island Destinations
}

Robertico R. Croes

University of Central Florida, robertico.croes@ucf.edu

Part of the Hospitality Administration and Management Commons, and the Tourism and Travel Commons

Find similar works at: https://stars.library.ucf.edu/ucfscholar

University of Central Florida Libraries http://library.ucf.edu

This Paper is brought to you for free and open access by STARS. It has been accepted for inclusion in Faculty Scholarship and Creative Works by an authorized administrator of STARS. For more information, please contact STARS@ucf.edu.

\section{Original Citation}

Croes, R. (2010). Measuring and explaining competitiveness in the context of small island destinations. Journal of Travel Research, 50(4), 431-442.

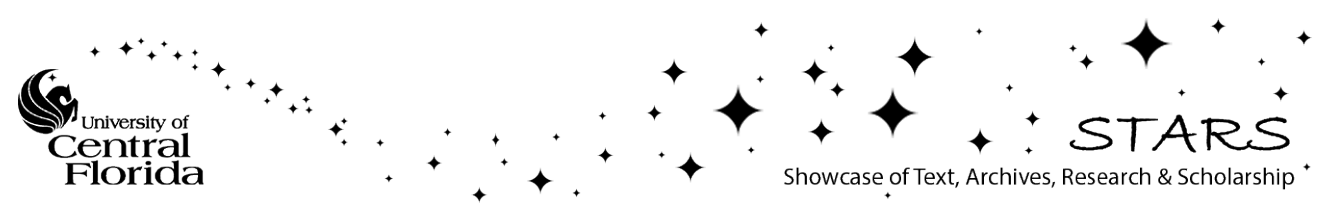




\title{
Measuring and Explaining Competitiveness in the Context of Small Island Destinations
}

\begin{abstract}
This study measures and explains competitiveness amongst small island destinations. Current measures of competitiveness do not respond to the special needs of small island destinations. An alternative measurement suggests a Tourism Competitiveness Index (TCI) more suited for small island destinations; and through the application of panel regression analysis, tracks the most important factors impacting competitiveness among island destinations. The findings imply likelihood that more expensive destinations obtain a larger share of regional tourism revenues. The study concludes that providing a high quality product may allow destinations to become and remain competitive.
\end{abstract}

Key words: competitiveness, small size, tourism index, panel regression analysis, Caribbean. 


\section{Introduction}

The purpose of this study is to measure and explain tourism competitiveness. Competitiveness has been associated in the tourism literature as a crucial factor for the success of tourist destinations (Kozak \& Rimmington, 1999; Crouch \& Ritchie, 1999; Mihalic, 2000; Buhalis, 2000; Dwyer \& Kim, 2003; Gooroochurn \& Sugiyarto, 2005; Enright \& Newton, 2005; Mangion, Durbaryy \& Sinclair, 2005; Mazanec et al., 2007; Chen, 2008). Tourism studies in general seem to imply that by being competitive a tourist destination could expand its tourism industry; hence, the quality of life of the populace (Crouch \& Ritchie, 1999; Dwyer \& Kim, 2003; Sahli, 2004; Kim, Chen \& Jang, 2006; Craigwell, 2007). Policy makers seem, therefore, eager to increase their market share of travel and tourism (Hawkins \& Mann, 2007). However, there is growing debate about the definition of and the means to measure competitiveness (Croes, 2005; Papatheodorou \& Song, 2005).

The definition and measurement of tourism competitiveness is receiving increased attention in the literature. The reason for this is threefold: (1) tourism as a sector has become increasingly important in global, national, and regional economies; (2) the competition among destinations has increased dramatically, but the originating markets have remained almost unchanged (Mak, 2003; Vanhove, 2005); and, (3) while tourism benefits in the short-term seem clear, its benefits in the long run are not self-evident (Sinclair, 1998; Nowak et al., 2003; Kim et al., 2006). Overall, destinations are compelled to enhance their performance in order to attract more visitation levels and spending (Crouch \& Ritchie, 1999; Dwyer, Forsyth \& Rao, 2000; Craigwell, 2007). 
This study focuses on competitiveness in small island destinations and provides a measurement that could examine the efficiency of tourism outputs thus contributing to recent tourism literature. As the number of small islands attempting to develop a competitive tourist activity is increasing, this strategy may be growth enhancing (Lanza \& Pigliaru, 2000; Brau, Lanza \& Pigliaru, 2003; Shareef, 2004). From a competitive perspective, it appears that destinations with higher levels of tourist visitation may be perceived as better performing than those with lower levels of visitation. For example, in its vision of the Caribbean region of 2020, the World Bank used visitation levels to estimate the impact of tourism on job creation up to that time period (World Bank, 2000; 2005).

Tracking competitiveness through visitation levels and market share are neither accurate nor appropriate tourist performance tools to assist destination practitioners in their daily decision-making to achieve sustained competitiveness. These practices generate the wrong type of incentive structure for practitioners, thereby jeopardizing competitiveness in the long run. In addition, the more complex set of indicators of competitiveness as espoused in some global indices (e.g. World Economic Forum and the Travel and Tourism Competitiveness Reports) do not properly take into account the context, or descriptors, of destinations, such as those of small island tourist destinations (Wignaraja, Lezama, \& Joiner, 2004; Craigwell, 2007).

Two questions underlying this study are (1) how to measure destination competitiveness, and (2) how to explain the different levels of competitiveness among destinations. The study will draw from the works of Ritchie and Crouch (2003) and Wignaraja et al. (2004) and will create a new tourism competitive index more suited to 
small island destinations. The concept of economic value is used in order to explain the variance in competitiveness. Economic value provides a more robust and rigorous framework to explain these variances because the framework is derived from the rational choice theory. Panel regression analysis is used in order to explain the differences in performance output.

The Caribbean area is the most tourist dependent area in the world (World Bank, 2005) and is broadly defined as a regional agglomeration of small and vulnerable countries located in the Caribbean Sea. In this context, small size is defined as a population under 1.5 million inhabitants, per Commonwealth Secretariat and World Bank (2000). These countries are facing unprecedented adjustment challenges in the wake of the increasing process of globalization and are in search of appropriate policy responses to globalization. The economic growth potential of tourism has been highlighted in several recent studies (Hazari \& Sgro, 1995; Balaguer \& Cantavella-Jorda, 2002; Lanza et al., 2003; Dritsakis, 2004; Durbarry, 2004; Eugenio-Martin, Morales, \& Scarpa, 2004; Maloney \& Rojas, 2005; Eugenio-Martin, Martin-Morales \& Sinclair, 2008; Croes \& Vanegas, 2008; Sequeira \& Nunes, 2008). And, it is expected that tourism will continue to play an even greater role in propelling increased growth and economic opportunities for these small countries.

This article is organized as follows. The first section reviews and discusses the definition and measurement of competitiveness. The second section suggests a new tourism competitiveness index, and the third section proposes a model to explain variances among competing destinations. The fourth section looks at data collection and 
findings; and the fifth and final section discusses the conclusions and implications of the study.

\section{Defining and measuring competitiveness}

Defining competitiveness has been a cumbersome endeavor in the literature.

Definitions proliferate as more destinations appear in the global market place to compete for tourist dollars. Many destinations promote tourism precisely for generating foreign exchange and economic welfare benefits (Copeland, 1991; Sinclair, 1998; Kim et al., 2006; Sequeira \& Nunes, 2008) thereby promulgating performance measurement at the forefront of destination management. In this context, measurement is critical in providing timely and quality information for the purpose of designing, assessing goals, fostering learning, and amending organization and management performance.

Measurement seems proper only when it generates identification of the conditions that cultivate positive performance. Measuring the wrong things could jeopardize, for example, a destination's long run economic viability. Measuring seems also related to the future. For instance, indicators should lead to actions that could influence future outcome. Thus, measurement functions as a tool rather than an end in itself. Such considerations beg the discussion of "what" is to be measured; which, in essence, is related to the definition of the concept of competitiveness. In other words, what is "competitiveness," and what exactly is it that has to be measured in order to say that a destination is competitive?

Competitiveness is often benchmark against which success is measured (Porter, 1990; ECLAC 1990; Dollar \& Wolff, 1993; Krugman, 1996). However, whereas the discussion about the definition of competitiveness was focused mainly on price related 
factors, it is currently moving to non-price related factors, such as technology, innovation, etc. (Fagenberg, 1996; Lall, 2001; Wignaraja et al., 2004). Some studies have defined competitiveness either explicitly or implicitly as having more of something such as market share, profits, success, etc. than that of another destination. Destinations which enjoy more arrivals and more spending from tourists, or have benefited from a higher market share in the global market than others, are considered to be competitive (Sahli, 2006; Craigwell, 2007). This definition, however, reveals several shortcomings.

First, some destinations seek moderate growth rates of arrivals rather than seeking higher numbers of arrivals. So, definitions that are based on growth rates penalize the aforementioned destinations whose precautionary perspectives seem to run counter to sustainable practices. As a result, those destinations that base their measurement of competitiveness on prudent choice rather than on growth rates could be described as idle; the outcome of which could be a negative image and thus negative market appeal. This possibility is indeed unfortunate as, in actuality, a policy of sustainable tourism inevitably slows growth rates because it purports that unlimited growth will generate negative externalities and eventually lead to the industry's own destruction (Butler's life cycle hypothesis).

Second, destinations constrained by size are also penalized when performance is based on average growth rates. For example, in small island destinations, tourism supply is determined by the size, structure, and quality of tourist attractions, infrastructures and super structures, and the destination's management capabilities. As supply constraints may be limited factors, small countries' economies cannot grow consistently at the rates of larger countries. 
Finally, market share which seems the most widely used measure of competitiveness is an incomplete yardstick because of the relatively small share of the global/regional market of most island destinations. Also it lacks variance.

The most comprehensive definition about competitiveness has been crafted by Ritchie and Crouch (2003) whereupon by applying Porter's (1990) core diamond theory of competitive advantage, they provide a discerning framework distinguishing comparative from competitive advantages. The micro (e.g., business) and macro (e.g., nature, technology, etc.) environments are impacted by four distinct domains - qualifying and amplifying determinants: destination policy, planning and development; core resources and attractors; and supporting factors and resources - which lend themselves to the design of a conceptual model for destination competitiveness. Ritchie and Crouch (2003) define competitiveness as “... [the] ability to increase tourism expenditure, to increasingly attract visitors while providing them with satisfying, memorable experiences, and to do so in a profitable way, while enhancing the well-being of destination residents and preserving the natural capital of the destination for future generations"(page 2). This comprehensive definition seems to encompass some hidden assumptions in terms of cause and effect relationships. Ritchie and Crouch (2003) seem to imply that satisfaction generates increasing arrivals and that well-being of the residents is an outcome of profitability, for example.

The most comprehensive definition about competitiveness has been crafted by Ritchie and Crouch (2003) whereupon by applying Porter's (1990) core diamond theory of competitive advantage, they provide a discerning framework distinguishing comparative from competitive advantages. The micro (e.g., business) and macro (e.g., 
nature, technology, etc.) environments are impacted by four distinct domains - qualifying and amplifying determinants: destination policy, planning and development; core resources and attractors; and supporting factors and resources - which lend themselves to the design of a conceptual model for destination competitiveness. Ritchie and Crouch (2003) define competitiveness as “...[the] ability to increase tourism expenditure, to increasingly attract visitors while providing them with satisfying, memorable experiences, and to do so in a profitable way, while enhancing the well-being of destination residents and preserving the natural capital of the destination for future generations"(page 2). This comprehensive definition seems to encompass some hidden assumptions in terms of cause and effect relationships. Ritchie and Crouch (2003) seem to imply that satisfaction generates increasing arrivals and that well-being of the residents is an outcome of profitability, for example.

Delineating activities solely confined to competition with other destinations is not an easy task. The most striking feature of the above literature is the variety of the indicators proposed. Some pertain to inputs, others to outcomes, others to instruments. Some activities clearly imply competition with other destinations (such as arrival flows, bed-nights, value-added and customer satisfaction) while others only have an indirect effect on competition as inputs (such as land, parts of the infrastructure, transport and hotel services, etc.) In addition to indicators lacking in their relationship to competitiveness, some lack clear causal links.

Take, for instance, price. Purportedly, in some studies, (Dwyer, Forsyth, \& Rao, 2000) price is used as a factor impacting competitiveness. The example implies that price at the destination level would be a measure of the effective real exchange rate and unit 
labor cost. This would then imply that an appreciation of a destination's currency or an increase in labor cost would lead to a decline in the destination competitiveness.

Consider the countries in the top ten receiving destinations (as ranked according to the World Tourism Organization.) Would it be theoretically possible to explain high prices and high labor costs in developed countries or more mature tourist destinations while at the same time registering a high tourism performance? Logically, a rise in labor costs should lead to a decline in the competitiveness level of a destination, and thus a lower market share. However, empirical evidence indicates that over the long-term, market share for exports (tourism) and relative unit costs (or prices) tend to move together, (the so-called Kaldor paradox.) As pointed out by Ritchie and Crouch (2003), trade in tourism services has special characteristics and, due to the nature of the trade, price seems to loose its informative power. Nevertheless, by establishing a list of relevant variables and encouraging improvements in measuring, a comprehensive analysis of competitiveness is an important initial step.

Composite indices appear to be means to circumvent the problem raised by the richness of comprehensiveness and to synthesize the abundant and purportedly relevant information into a single number. A competitiveness index is a composite measurement ranking countries based on a wide range of criteria and factors that could affect national competitiveness. Several composite indices such as the Global Competitiveness Report of the World Economic Forum (WEF), the World Competitiveness Report prepared by the International Institute for Management Development (IMD), and the World Travel and Tourism Council Competitiveness Report (2008) have been used to rank countries based on a wide range of criteria and factors that could affect national competitiveness. 
These rankings have been the object of criticism. Lall (2001) disclosed ranking flaws especially on definitional, modeling, determinant, and indicator aspects of competitiveness, reiterating the inadequacy of such indices for explaining the level of competitiveness in small countries.

For example, the 2008 Global Competitiveness Report and the Travel and Tourism Competitiveness Report which rank 138 countries, only mention and rank 12 small countries as defined by the 1.5 million population threshold. The reason for this lack of coverage is unclear, but it seems that these indices might not shed light on the specific issues and challenges confronting these countries, in that many of these variables take no notice of the destination's market size, the degree of dependence on tourism, the current state of economic development, or the vulnerabilities inherent in small size.

The only study which examines tourism competitiveness in the context of small destinations is that of Craigwell (2007). Craigwell uses the WTCC index to measure tourism competitiveness among Caribbean destinations. This index consists of eight separate indicators: price, human tourism, infrastructure, environment, technology, human resources, openness, and social aspects. The main shortcoming of this index is similar to the shortcoming of other indices. Namely, it lacks a clear understanding of a cause-effect relationship. For example, in the ranking of Caribbean countries based on the WTCC index, the countries with the highest ranking seem to reveal the least price competitiveness in terms of their tourism product.

The only consent in the tourism literature about competitiveness seems to be that competitiveness is related to the ability of destinations to compete with one another. This ability refers to policies that increase the economic potential of a destination aiming at 
generating new jobs and better living conditions (Porter, 1990; Dollar \& Wolff, 1993;

Krugman, 1996; Crouch \& Ritchie, 1999; 2006; Ritchie \& Crouch, 2003; Dwyer \& Kim, 2003). In other words, competitiveness seems to be an antecedent for economic welfare and prosperity of the population by fostering the ability of a destination to raise tourism spending and to provide memorable experiences to tourists while simultaneously preserving the integrity of its natural capital (Crouch \& Ritchie, 1999; Ritchie \& Crouch, 2003). As there seems to be systematic price and quality differences among destinations, competitiveness outcomes may be the result of policies rather than just random results. Thus, destinations' policies are potentially important because they apply key inputs (e.g. climate, beaches, beautiful sights, infrastructure, safety and security, and cleanliness) that contribute to the production of tourism services. This may explain why some destinations are successful in promoting tourism, and why others seem to fail.

This reason in itself is a potent argument not to insist on the abandonment of the concept of competitiveness because formulation and coordination at the macro level could increase competitiveness at the micro level. Unlike Krugman (1996) who argues against the futility to trust governments in building dynamic comparative advantage, it is argued here that tourism development is not about tackling impediments to optimal resource allocation due to the degree of existence of market failures and the stage of economic development of a country. Instead, tourism development lies in overcoming the nature of market imperfections caused by the nature itself of tourism production and consumption. This condition makes intervention theoretically justifiable and takes the concept of competitiveness beyond its initial intuitive appeal and into the realm of studying the ability of destinations to compete with each other. This ability refers to 
policies that increase the economy's potential of a destination implying that tourism can only develop or function with regular and robust government management. In the context of small island destinations, internal markets are small and not powerful enough to be the engine for national development.

However, evidence indicates that the outcome of the ability of destinations to compete is mixed, because the link between tourism numbers (arrivals and expenditures) and economic contribution to the quality of life is not always obvious (Adams \& Parmenter, 1995; Dwyer \& Forsyth, 1998; Shan \& Wilson, 2001; Balaguer \& CantavellaJorda, 2002; Lanza et al., 2003; Dritsakis, 2004; Durbarry, 2004; Eugenio-Martin et al., 2004; Maloney \& Rojas, 2005; Oh, 2005; Kim et al., 2006; Eugenio-Martin et al., 2008; Croes \& Vanegas, 2008; Sequeira \& Nunes, 2008). This apparent reality suggests the need to define a causal model in terms of leading indicators that therefore enable the conditions that cultivate performance. Before examining this important issue, the next section of the study will proceed to measure performance.

\section{The Tourism Competitiveness Index}

Past studies were want to distinguish relevant from irrelevant variables with a propensity to use large numbers of variables without theoretically justifying their causal relations to the dependent variable (and often without measuring them correctly.) In addition, these variables fail to take into account the nature of the destination (size of the market), the degree of dependence on tourism, the destination life cycle or its stage of economic development. These variables (e.g., price or human resource factors) may impact tourism demand differently in comparing large with small destinations, thereby rendering these comparisons or benchmarking futile. For example, the study of 
Gooroochurn and Sugiyarto (2005) compares the United States tourism capability with that of Malta or Barbados, two small destinations assessed in their studies without considering scale effects.

Most of the studies skate over important theoretical issues, such as factor interaction. The question is, how to theoretically explain the presence of high prices and high labor costs as occurring in developed countries or more mature tourist destinations while at the same time realizing a high tourism performance, such as that of the countries ranked by the WTO as being in the top ten receiving destinations in the world. Surely, a rise in labor costs could lead to a decline in the competitiveness level of a destination, which would translate to a lower market share. However, empirical evidence indicates that over the long-term, market-share for exports (tourism) and relative unit costs or prices tend to move together (Kaldor paradox.) Smeral (2003) stressed this point when he observed that while tourism exports in the OECD countries grew at an average of $7.7 \%$ annually since 1980, tourism export prices increased twice as fast as export prices for manufactured goods during that same period.

Wignaraja et al. (2004) in their study about competitiveness of small countries tracked and ranked manufactured export competitiveness. Unlike other studies, they considered the needs of the small countries, the corresponding data requirements to cover as wide a range as possible of small countries, and the effects of small destination size. This analysis draws from and builds on the Wignaraja et al. (2004) study. The present study departs from a data sparse context of small islands to focus on the national ability to produce tourism competitively in constructing the competitive index. The definition of competitiveness is borrowed from the Ritchie and Crouch's study (2003), and focuses on 
two variables: satisfaction as the driver for demand and productivity as the creation of value in the use of resources. When used in conjunction with one another, these variables represent a blend of demand and supply that purportedly measures lower than average productivity gains of supply (Smeral, 2003) which are compensated through high demand elasticity to income from tourism; thereby potentially generating the terms of trade gains (Lanza \& Pigliaru, 2000). This claim assumes that higher demand in tourism and productivity may propel economic prosperity. The assumptions of the index are therefore derived from the optimizing models, i.e., destinations attempt to maximize tourism receipts.

From this optimizing perspective, growth in output should exceed the contribution of the inputs. In this context, productivity refers to the efficient use of resources and factors of production and the capacity of an economy to raise (or at least keep) the standard of living of the population. Productivity gains appear to be the mechanism for national competitiveness (Porter, 1990; Dollar \& Wolff, 1993; Krugman, 1996;

Faberberg, 1996; Crouch \& Ritchie, 1999, 2005). Competitiveness is therefore associated with the ability of a destination to raise tourism spending and to provide memorable experiences to tourists, while enhancing the quality of life of the residents and simultaneously preserving the integrity of its natural capital (Ritchie \& Crouch, 2003). The index will not only be determined by factor conditions (added value) as they impact attractiveness (Ritchie \& Crouch, 2003), but the index will also include the examination of productivity growth proxied by the growth in receipts per capita. Finally, the index will include scale effects to reflect the size of destinations. 
The TCI enables a quick global view of the performance of a destination: a destination which scores low on the ranking list could quickly look at the variables affecting this score and assess how to improve its ranking along the variables. Furthermore, the requirement of richness of data so conspicuously present in other studies is replaced by the convenience of data availability based on observations of outcomes of productivity and satisfaction of the tourists. The normative issue of defining preferences is avoided through the assumption that observed spending by the tourist reveals the true preference of people. Finally, it focuses on outputs which allows for simple comparisons of tourism performance over time and across destinations. Given that data referencing a small island destination's outputs are readily available, reliable, and without substantial costs (e.g. financial and human resources) outputs may be incorporated in the estimation of the composite number. In addition, it adds dynamic features to the ranking system of destinations while taking specific economic structures and performance of those destinations into account. From this perspective, this study proposes a shift in index analysis from richness to simplicity.

The TCI is thus composed of three outputs, each capturing a different aspect of the industry's productivity as it relates to small island destinations and is combined to create a quick snapshot of where a destination stands in terms of competitiveness. The three outputs are as follows:

1) current performance in the global tourism market scaled by size

2) dynamism of performance over time (growth rates)

3) size of the industrial base in the economic structure 
The first factor depicts the actual record of a destination to compete in the global market rather than simply alluding to the ability to compete. The second factor refers to how dynamic this performance is and will provide an idea about the trend in performance, while the third will assess the structural realities of the specific industry. Specifically, the three outputs will use the following variables: tourism receipts per capita in 2006 (US\$); average tourism receipts growth rates from 1986 to 2006; and tourism added value as a percent of the GDP in 2006.

An index value will be estimated for each variable based on the following formula:

$$
X_{c i}=\frac{X_{c_{i}}-X_{c_{\min i}}}{X_{c_{\max i}}-X_{c_{\min i}}}
$$

Where $c$ represents country and $i$ indicates the variables.

The maximum and minimum values were derived from the sample of countries and the three variables were weighted 40:30:30 in order to reflect the relevance of the size issue,

following Wignaraja et al. (2004). This index should provide the study with a ranking of destinations. Once the ranking has been established and analyzed, the study will proceed to explain the variance in ranking through the concept of economic value.

\section{Explaining Competitiveness through Economic Value}

For purposes of this study, the concept of economic value derives from rational choice theory which defines value from the perspective of the consumers' use of a good. In other words, value is construed in terms of "use," such as that value resulting from visiting a particular destination. Within this context, the study presumes that individual 
consumers use their income to buy marketed goods, and combine these goods with time, knowledge, and non-market goods to provide a more preferable quality of life.

Rational choice theory infers, therefore, that the value consumers place on a product can be identified by observing their actual consumption of the product without having to discuss the reasons or motives behind their choice. From this perspective, it can be stated that a consumed good provides greater utility than a good that has not been consumed. Thus, for example, consuming Barbados rather than Antigua means that the Barbados product provides greater utility to the consumer than the Antigua product.

Many of the characteristics in tourism seem to have a relatively low marginal utility, but a high total utility to tourists, because a large portion of tourism inputs consists of un-priced goods, such as weather, beaches, mountains, historic buildings and other cultural resources. Therefore, the utility function in tourism could be $U(X, R)$, where $\mathrm{X}$ represents goods purchased in the market combined with a non-market resource, R. Let $\mathrm{p}$ be the vector of market prices corresponding to $\mathrm{X}$. By making the usual assumptions about the properties of utility functions and considering $\mathrm{R}$ to be a conventional good, we may define an expenditure (cost) function in terms of: $\mathrm{C}(\mathrm{p}, \mathrm{R}, \mathrm{u})^{*}=\min \left\{\mathrm{xp} \mid \mathrm{U}(\mathrm{X}, \mathrm{R})=\mathrm{u}^{*}\right\}$, where $\mathrm{u} *$ is a reference level of utility.

In other words, $\mathrm{C}$ expresses some minimum level of costs in achieving utility based on some resource level, R. The study assumes that these costs are associated with the types of minimum required levels of investments in infrastructure, education, and safety which would secure demand. Other tourism resources (e.g., land, water assets, and historic buildings) while of little value in other economic sectors are invaluable from a tourist perspective as those resources do not conflict with other economic activities to 
which tourists subscribe (Zhang \& Jensen, 2007). This low opportunity cost is especially salient in small island destinations where other economic alternatives seem scarce (Candela \& Cellini, 1997).

Based on the definition of utility, the study uses price as a proxy for value, defined as the log of tourist receipts per arrival in US\$. After all, the price paid reflects very well how much a consumer values products. Price movement in this context (i.e., increase or decline) should be interpreted as a change in the scarcity of products relative to other products. High value, therefore, is associated with high expenditure tourist performance and thus the potential for higher multipliers: while low value is associated with a low-spending tourist. Destinations entertaining low spending tourists may have a higher externality cost in congested areas, substandard road conditions, and pollution, reducing the carrying capacity of the destination; thereby negatively affecting the value of the tourist product (the TALC factor) (Moore and Whitehall, 2005). The low spending tourists in this context may cause the destination to enjoy less value. It is possible for a tourism destination to earn more with higher priced products rather than with more arrivals. Finally, greater value could be the result of higher income in the originating markets and/or some destination specific conditions, such as technological advantage, industrial organizational advantage and attractiveness (Bull, 1995; Sinclair \& Stable, 1997; Mak, 2004; Vanhove, 2005)

$$
\mathbf{V}=\Pi(I, P, D, C)
$$

Where $\mathrm{V}$ is Value at a destination, I is income in originating markets, $\mathrm{P}$ is price level at the destination, D stands for destination specific conditions, and C stands for the cost of investment and the maintenance cost of the infrastructures. The study is interested 
in explaining changes in $\mathrm{V}$ from period $\mathrm{t}-1$ to period $\mathrm{t}$ resulting from deviations in competitiveness conditions relative to other destinations:

$$
\mathrm{v}_{i}(\mathrm{t})-\mathrm{v}_{i}(\mathrm{t}-1)=\mathrm{a}_{t}+\varphi \mathrm{X}_{i t-1}+\mu_{i t}
$$

where $\mathrm{X}_{i}$ is a vector of variables that influence the competitiveness of a tourist destination, $i$. In applying a panel data representation to capture the unobservable differences among destinations, a reduced form of the structural model can be expressed as:

$$
\mathrm{v}_{i}(\mathrm{t})-\mathrm{v}_{i}(\mathrm{t}-1)=\mathrm{a}_{t}+\varphi \mathrm{X}_{i t-1}+\alpha_{i}+\eta_{i}+\mu_{i t}
$$

where $\alpha_{i}$ and $\eta_{i}$ are respectively individual and temporal effects. If there are persistence/reputation effects that apply over time (for example, repeat visitation), then this should be incorporated in the model. This means incorporating dynamics into the model for which the adjusted equation in essence becomes AR(1) model:

$$
\mathrm{v}_{i}(\mathrm{t})-\mathrm{v}_{i}(\mathrm{t}-1)=\mathrm{a}_{t}+\varphi \mathrm{v}_{i}(\mathrm{t}-1)+\mathrm{X}_{i t} \beta+\alpha_{i}+\eta_{i}+\mu_{i t}
$$

where $\Delta \mathrm{v}_{i}(\mathrm{t})=$ the $\log$ difference in value over a period $; \mathrm{v}_{i}(\mathrm{t})=$ the $\log$ of value at the start of that period ; $\mathrm{X}_{i t}=$ the vector of explanatory variables as described previously ; $\mathrm{a}_{t}=$ period-specific intercept terms to capture changes common to all destinations ; $\alpha_{i}=$ the unobserved destination-specific and time invariant effects (unobserved fixed effects); and $\mu_{i t}=$ the time variant idiosyncratic error term. First differencing is used to remove the individual effects and to solve the omitted variable bias(Song \& Witt, 2000 ; Wooldridge, 2002 ; Hsiao, 2003 ; Eugenio-Martin, 2008). This produces the following equation : 


$$
\Delta \mathbf{Z}_{i t}=\Delta \sum_{j=1}^{p} Z_{i t-j}+\Delta \mathbf{W}_{i t} \boldsymbol{\gamma}+\boldsymbol{\varepsilon}_{i t}
$$

\section{Econometric Model and Data Collection}

Typically, most empirical studies in tourism use time series approaches. Song \& Witt (2000) and Eugenio-Martin et al (2008) addressed a number of critical issues associated with these approaches and suggested instead the use of panel analysis in order to take care of unobserved country effects, endogeneity, outliers, dynamics and model uncertainty. This study uses panel data and more appropriate estimation procedures in order to depict the performance differences observed previously.

The model is estimated in double log form. The study used the autoregressive specification, because using the economic value as the measurement for tourism competitiveness would display the characteristics of a persistent series. However, idiosyncratic shocks to an island destination are likely to "hold memory," and, hence, could display unit root symptoms. In order to empirically establish the reason for the variance in competitiveness across the small island destinations, and considering the multiplicative function of the panel data approach, the dynamic double log form is annotated as follows:

$$
\begin{aligned}
& \Delta \ln (\text { Value })_{i t}=\beta_{1} \Delta \ln \left(\text { Value }_{i, t-1}+\beta_{2} \Delta \ln (\text { Arrival })_{i t}+\beta_{3} \Delta \ln (\text { Price })_{i t}+\beta_{4} \Delta \ln (\text { Real GDP }\right. \\
& \text { per Capita })_{i t}+\beta_{5} \Delta \ln (\text { Cost })_{i t}+\Delta \varepsilon_{i t} \\
& \text { where } i=1, \ldots, 9 ; \mathrm{t}=1999, \ldots, 2005 \text {. Because all the variables used are in double- } \\
& \text { logarithmic form, the parameters may be interpreted as elasticities. The estimated }
\end{aligned}
$$


coefficients are short run elasticities and by dividing each of the coefficients by $\left(1-\beta_{1}\right)$ the long-run elasticity is obtained.

Index $i$ represents the island destination, while index $t$ covers the year in question: $\alpha_{i}$ refers to the structural coefficients (see Table 1$) . \ln \left(\right.$ Value) ${ }_{i t}$ is the log of the economic value generated by tourism in destination $i$ during year $t$ and is defined by the growth rate of the actual value consumed of the tourist stay (changing rate of spending per arrival). The log of arrivals refers to the visitation level in year $t$ to the destination and is a proxy for cost; the $\log$ Price captures the relative price of different destinations and is defined as the ratio of receipts in $i$ during year $t$ to the total of the region during year $t$. The log GDP per Capita is a proxy for local productivity levels and hence locally available technology, and amenities that are known to be strongly correlated with the destination's economic development (e.g., security, transportation, and infrastructure). The log Cost captures the costs associated with investment and maintenance of the tourism industry and is defines as the hotel capacity in destination i during year $\mathrm{t}$.

*******INSERT TABLE 1******

The theoretical expectations for the proposed model are: (1) arrivals are nonlinear functions with positive initial effects; but eventually may indicate a negative relationship with Value - therefore it may be positive or negative; (2) Value increases as Price increases; and (3) Value increases with attractiveness.

In order to address endogeneity bias created by the unobservable destinations' differences in correlation with the regressors of interest, the study selects a fixed effects 
specification, where the destinations' fixed effects are denoted by $\mathrm{c}_{i}$. This step is intended as a control for the average differences in the unobservable predictors, such as differences in quality, policies, and attractiveness of the destination. In addition, the study included year fixed effects $\mathrm{d}_{t}$ to address weather changes and macro economic characteristics of tourism demand over time. Finally, $\varepsilon_{i t}$ covers the unexplained shocks. The study assumes these shocks to have constant variance and to be serially uncorrelated to the predictors.

\section{The Caribbean}

The sample of countries consists of members of the Caribbean Tourism Organization (CTO). These countries reflect regional diversity, varied market orientations and a range of experiences, from emerging to long-standing destinations. Country inclusion was based on two criteria: (1) having a population of less than 1.5 million; and, (2) convenience (e.g. availability of data). In 2006, CTO members received 22.2 million stay-over arrivals with a total spending of $\$ 21$ billion US dollars. With less than $1 \%$ of the world's population, it consistently attracts $3 \%$ of the global tourism business.

Despite this regional performance, competition among Caribbean destinations has become increasingly fierce in the last 20 years thereby exacerbating growth opportunities for these small islands (World Bank, 2005). As growth intensifies and reinvigorates the industry, there is implication that updating strategies in order to seize emerging opportunities in the market place would be wise. Using performance indicators to provide guidelines for modifying, altering, or changing strategies could assist the destinations in their quest for remaining competitive. 
To assess that level of competition, the study applied the Hirschman-Herfindahl Index (HHI) to measure the relative distribution of international receipts of all destinations over a period of time. A perfectly competitive environment will have a value of 100 with a decline in the degree of competition reflected in higher index estimates. The graph in Figures 1a and $1 \mathrm{~b}$ plots the trend of the Caribbean experience. Figure 1(a) can be construed that the experience indicates fluctuations in competition. It also indicates that there is a decreasing trend in competition in the region as a whole despite that the HHI remains still below the 110 mark. If, however, we remove the bigger Caribbean islands (e.g. Cuba, Dominican Republic, Puerto Rico, etc.) from the comparison and only assess the degree of competition among small island destinations in the region (see Figure 1b), there seems to be a higher degree of competition among the destinations as displayed by the lower estimates in HHI.

*******INSERT Figure 1*******

The results in performance indicate that there are significant differences among the destinations. We expect therefore that the intercepts would differ among destinations suggesting the need for fixed effects models to assess and explain the differences in performance. In the next section, the study assesses the relative performance of the destinations in this competitive environment.

\section{Data Collection}

The study used annual data and the estimation covered the period 1999 to 2005. 
Data for this study were collected from the World Tourism Organization (WTO), the Caribbean Tourism Organization (CTO), the World Travel and Tourism Council

(WTTC), and the International Financial Statistics of the International Monetary Fund (IMF). The data covers a time span from 1986 to 2006.

\section{Study results}

Table 1 provides the ranking for the 16 destinations with their component indices, the ranking in each individual variable, and the underlying data estimates. It is interesting to note that there are considerable differences in the ranking across the three variables top performers in one variable are not necessarily the top performers according to the two other variables. For example, Martinique displays a commendable performance in growth rates of the past 20 years (rank number 2), but underperformed in the other two variables (ranks 14 and 16 in spending per capita and the share of the industry base in the wider economy, respectively). On the other hand, Aruba shows consistency among all three criteria ranking 3, 3, and 2, respectively. St Kitts and Nevis also displays consistency in the three rankings albeit close to the bottom end. Some destinations, such as Barbados and Bermuda did not perform as well as might be expected.

What seems to distinguish the top five performers from the five laggards is their rank with regard to spending per tourist and tourism value added. Aruba, British Virgin Islands, Anguilla, US Virgin Islands and Antigua and Barbuda scored fairly high in those rubrics whilst St. Kitts and Nevis, Barbados, St. Vincent and the Grenadines, Martinique, and Bermuda underperformed, indicating an erosion of their comparative competitiveness over the last two decades. The study indicates that destinations seem systematically different from each other in terms of performance. The question arises as to why some 
destinations might vary in performance from others. The study therefore investigates these cross-destination differences.

The study performed the diagnostic tests in order to determine whether the data can be pooled and whether to use a fixed effect or random effect model. The pooled model assumes that there is no heterogeneity among destinations and no fixed effects are estimated. It assumes that the intercept and the other parameters are the same across destinations. The fixed effects model, on the other hand, assumes that destinations are heterogeneous and estimate destination specific effects. This model is unrestricted compared to the pooled model because it allows for an intercept and other parameters to vary across destinations. The $\mathrm{F}$ test is performed to test for poolability of destinations. The F-statistic turned out to be quite large: $F(8,50)=85.47(\mathrm{p}<.0000)$, thereby rejecting the null hypothesis (the null hypothesis is that all dummy parameters except one are zero: $\left.\mathrm{H}_{0}: \mu_{1}=\ldots=\mu_{n-1}=0\right)$. This means that a model with individual effects must be selected.

The next step was to distinguish between fixed effects and random effects models. The main difference between the two lies in the role of the dummies: if dummies are considered as part of the intercept, this is a fixed effect model; alternatively, if dummies act as an error term, then it is a random effect model. The Hausman specification tested which model is more appropriate in the study's measurement of small island destination competitiveness. The Hausman test was 36.59, revealing that the null hypothesis of no correlation should be rejected, i.e., the destination specific effects are thus correlated with regressors and suggest that the fixed effects model is appropriate.

The data was then transformed to the first difference in order to remove the destination effects. Before performing the regression analysis, a panel unit root test was 
performed by applying the Levin, Lin and Chu test (LLC) (2002). The test assumes common unit root process meaning that all members of a panel have unit roots $\left(\mathrm{H}_{0}: \mathrm{p}_{i}=0\right.$

for all $i$, and the alternative hypothesis is that all members of a panel are level stationary $\left(\mathrm{H}_{1}: \mathrm{p}_{i}=\mathrm{p}<0\right.$ for all $\left.i\right)$. The LLC test would reject the unit root hypothesis only if all the destination effects are stationary in each panel. The results obtained are reported in Table 2. The results indicate that not all members of the panel are level stationary thereby accepting the unit root hypothesis. The LLC test of the first differences rejects the null hypothesis, thus suggesting the existence of convergence at the panel level.

*******INSERT TABLE $2 * * * * * * *$

Table 3 gives the estimation results for the fixed effect models. All the variables, i.e., arrivals, technology, price, and investment are significant and demonstrate the expected direction of the relationship. The income per capita regressor is positive and significant meaning that created assets and technology is an important determinant of competition. Similarly, investment in infrastructure is disclosed as positive and significant. In addition, the price factor appears important in determining the competitive level of a destination. More expensive destinations seem more able to obtain larger shares of regional spending of tourism, thereby indicating evidence of the Kaldor paradox in the tourism industry for these destinations. This result disconfirms the findings from previous studies (Dwyer et al, 2000, 2002). The arrival factor, as expected, turned out negative and statistically significant thereby indicating that increased numbers of tourists could jeopardize the value of the destination. It appears that arrivals are closely related to the 
carrying capacity of small island destinations and decreasing marginal utility thereby affecting the willingness of tourists to pay.

*******INSERT TABLE $3 * * * * * *$

Finally, the results indicate that dynamic effects take place in two different modes; i.e., through changing reputation levels which are captured by the influence of the previous time period on the spending behavior of the current period; and second, by making a distinction between a long-run equilibrium towards which competitiveness appears to be moving from its current position. The spending per tourist as measured in the prior period tends to have a negative effect on the current spending behavior of the tourists. Thus, it seems that tourists were not entirely satisfied by the tourist services they received in the destination. Alternatively, repeat visitation may be prominent in these destinations and these repeat visitors are known for reducing the search cost at a destination for less expensive tourist services.

\section{Conclusions and Implications}

The goal of the study was to investigate tourism competitiveness amongst small size island destinations. Small size is defined as a destination with a population of less than 1.5 million inhabitants. The extensive literature review indicates that small island destinations so far have been ill served in the debate about competitiveness. Their needs

and special characteristics have not been taken into account by the existing literature nor do the existing competitiveness indices suit their challenges in an ever changing global 
world. Two relevant and interrelated questions about competitiveness as they pertain to small island destinations were answered; namely, (1) how to measure destination competitiveness; and, (2) how to explain the different levels of competitiveness among destinations. The Caribbean region was used as the case study because it reflects regional diversity, varied market orientations and a range of experiences, from emerging to long-standing destinations, and is a region that is comprised of a large amount of small island destinations.

The study applied the Hirschman-Herfindahl Index (HHI) to measure the relative distribution of international receipts of all destinations over a period of time. It found that there exists a clear pattern in increased competition in the region over the period reviewed. The study constructed next a Tourism Competitiveness Index to address the issue of the level of competition. Contrary to previous indices this study incorporates size, dynamism and structure specifically related to small island destinations.

A panel regression analysis was used in order to explain the differences in performance output. The results indicate that there are clear differences in patterns of performance amongst small island destinations. Why are some destinations more successful than others? In other words, how are the variations in performance explained? The estimated results of the model of tourism competitiveness indicate that the determinants of tourism value depend on the level of arrivals, price, the level of development of the destination and the level of investment in the infrastructure of the tourism industry. The results further indicate that previous experience with a destination tends to have a negative impact on the spending behavior of the visitor. 
The results imply that competitiveness is related to the ability of the destination to create and nurture a high quality product. Like any other industry, tourism requires sophisticated planning and technological inputs in order to extract premium prices. It requires a consistent consideration for the tastes and preferences of tourists and the manipulation of service approaches and strategies to adjust to those tastes and preferences, which then enables destinations to continue to be successful in the marketplace. High prices may therefore signal quality and may serve to minimize the likelihood of quality deterioration thereby attracting higher spending tourists (a virtuous circle). Clearly then, small island destinations cannot rely on their natural beauty alone. An increase in prices could lead to a theoretical paradox. Conventional measurement of competitiveness suggests that an increase in prices may render a destination uncompetitive and the policy implication is that a destination should focus on a reduction of export prices in order to increase competitiveness. But this would lead to a reduction in welfare. How could this paradox be resolved? If the problem consists in dealing with the expected fall in demand due to rising prices, then the solution could be sought in making the product more attractive (non-price competition). In other words, the solution is considering the tastes and preferences of tourists in a creative and consistent way and the manipulation of service approaches and strategies to adjust to those tastes and preferences. In this way tourists goods could be increasingly valued in international markets thereby offsetting the purportedly increase in cost production. This approach could propel long-term sustainability for small island destinations. Tourist goods should therefore be the result of the ability of a destination to connect supply side activities (e.g. attractions, services, infrastructures) with demand side value creation in order to satisfy 
the customers (marginal utility) through fulfilling "memorable experiences" which may affect the quality of life for its population.

The results of the panel regression should be interpreted with the necessary caveat. The Caribbean is a sub sample of the population of small island destinations, but it is not necessarily representative of the complete population. Some indicators may appear significant in the Caribbean sub sample, but this does not mean that they may be significant in another sub sample of destinations. The only way to prevent this problem of more homogenous sampling is to include all small island destinations that comply with the definition of size as used in this study.

Small Island Destinations are well served in using performance indicators because they provide guidelines, they correct for inefficient management directions, and they promote positive effects of competition amongst destinations. The study discusses the importance of using the proper performance indicators. It also provides an approach to produce simple indicators that summarize the elements that distinguish destination abilities and conditions that are crucial to the policy mechanisms in order to improve the ability to compete. These distinguishing abilities and conditions reveal that it may be necessary to control for arrivals of tourists. In addition, consideration for the right combinations of the levels of investment in the infrastructure, and creative technological assets may be necessary in order to forge a high quality product. In spite of the controls, the study implies that the more expensive destinations are likely to obtain a larger share of the regional tourism revenues. The extent of that share is an implication for future research. 


\section{References}

Adams, P. D. \& Parmenter, B. R. (1995). “An Applied General Equilibrium Analysis of the Economic Effects of Tourism in a Quite Small, Quite Open Economy." Applied Economics, 27 (10): 985-994.

Balaguer, J. \& Cantavella-Jorda, M. (2002). "Tourism as a Long-run Economic Growth Factor: the Spanish Case." Applied Economics, 34 (7): 877-884.

Brau, R., Lanza, A. \& Pigliaru, F. (2003). How Fast are the Tourism Countries Growing? The Cross-country Evidence.” FEEM, Working Paper No.85, Milan.

Buhalis, D. (2000). "Marketing the Competitive Destination of the Future." Tourism Management, 21 (1): 97-116.

Bull, A. (1995). The Economics of Travel and Tourism. Longman, South Melbourne, Australia.

Candela, G. \& Cellini, R. (1997). Countries' Size, Consumers' Preferences and Specialization in Tourism: A Note. Rivista Internazionale di Scienze Economiche e Commerciale, 44: 451-457.

Chen, C. Y. (2008). "Evaluating the Competitiveness of the Tourism Industry in Cambodia: Self-assessment from Professionals." Asia Pacific Journal of Tourism Research, 13 (1): 41-66.

Commonwealth Secretariat and World Bank (2000), Small States: Meeting Challenges in the Global Economy, Report of the Commonwealth Secretariat-World Bank Joint Task Force on Small States, Commonwealth Secretariat and World Bank.

Copeland, B.R. (1991). “Tourism, Welfare, and De-industrialization in a Small Open Economy." Economica, 58: 515-529.

Craigwell, R. (2007). Tourism Competitiveness in Small Island Developing States, World Institute for Development Economics Research, Research Paper No. 2007/19.

Croes, R. (2005). "Value as a Measure of Tourism Performance in the Era of Globalization: Conceptual Considerations and Empirical Findings." Tourism Analysis, 9 (4): 255-267.

Croes, R. \& Vanegas, Sr, M. (2008). "Cointegration and Causality Between Tourism and Poverty Reduction.” Journal of Travel Research, 47 (1): 94-103.

Crouch G. I. \& Ritchie, J. R. B. (1999). "Tourism, Competitiveness, and Societal Prosperity." Journal of Business Research, 44 (3): 137-152. 
Crouch, G.I. and Ritchie, J.R.B. (2006). "Destination Competitiveness." In International Handbook on the Economics of Tourism, edited by Dwyer, L. and Forsyth, P. Edward Elgar Publishing, Northampton, MA.

Dollar, D. \& Wolff, E. N. (1993). Competitiveness, Convergence, and International Specialization. MIT Press, Cambridge, MA.

Dritsakis, N. (2004). "Tourism as a Long-run Economic Growth Factor: an Empirical Investigation for Greece Using Causality Analysis.” Tourism Economics, 10 (3): 305316.

Durbarry, R. (2004). “Tourism and Economic Growth: the Case of Mauritius.” Tourism Economics, 10 (4): 389-401.

Dwyer, L., Forsyth, P. \& Rao, P. (2000). "The Price Competitiveness of Travel and Tourism: a Comparison of 19 Destinations." Tourism Management, 21 (1): 9-22.

Dwyer, L., Forsyth, P. \& Rao, P. (2002). "Destination Price Competitiveness: Exchange Rate Changes Versus Domestic Inflation." Journal of Travel Research, 40 (3): 328-336.

Dwyer, L. \& Kim, C. (2003). "Destination Competitiveness: Determinants and Indicators." Current Issues in Tourism, 6 (5): 369-414.

ECLAC (1990). Changing Production Patterns with Social Equity. ECLAC, Santiago, Chile.

Enright, M. \& Newton, J. (2004). "Tourism Destination Competitiveness: a quantitative approach.” Tourism Management, 25: 777-788.

Enright, M. J. \& Newton, J. (2005). "Determinants of Tourism Destination Competitiveness in Asia Pacific: Comprehensiveness and Universality." Journal of Travel Research, 43 (4): 339-350.

Eugenio-Martin, J.L., Martin-Morales, N. \& Scarpa, R. (2004). Tourism and Economic Growth in Latin American Countries: a Panel Data Approach, FEEM Working Paper No.26, Milan.

Eugenio-Martin, J.L., Martin-Morales, N. \& Sinclair, M.T. (2008), "The Role of Economic Development in Tourism Demand." Tourism Economics, 14 (4): 673-690.

Fagerberg J. (1996). "Technology and Competitiveness." Oxford Review of Economic Policy, 12 (3): 39-51.

Gooroochurn, N. \& Sugiyarto, G. (2005). "Competitiveness Indicators in the Travel and Tourism Industry.” Tourism Economics, 11 (1): 25-43. 
Hawkins, D. E. \& Mann, S. (2007). “The World Bank's Role in Tourism Development.” Annals of Tourism Research, 34 (2): 348-363.

Hazari B. R. \& Sgro, P. M. (1995). "Tourism and Growth in a Dynamic Model of Trade." The Journal of International Trade \& Economic Development, 4 (2): 43-252.

Hsiao, C. (2003). Analysis Panel Data, $2^{\text {nd }}$ Edition. Cambridge University Press, Cambridge.

Kim H. J., Chen M. H. \& Jang, S. C. S. (2006). "Tourism Expansion and Economic Development: The case of Taiwan." Tourism Management, 27 (5): 925-933.

Kozak, M. \& Rimmington, M. (1999). "Measuring Tourist Destination Competitiveness: Conceptual Considerations and Empirical Findings." International Journal of Hospitality Management, 18 (3): 273-283.

Krugman, P. (1996). "Making Sense of the Competitiveness Debate." Oxford Review of Economic Policy, 12 (3): 17-25.

Lall, S. (2001). "Competitiveness Indices and Developing Countries: An Economic Evaluation of the Global Competitiveness Report." World Development, 29 (9): 15011525.

Lanza, A. and Pigliaru, F. (2000). "Why are Tourism Countries Small and Fast Growing?" Edited by Fossati, A. and Panella, G. In Tourism and Sustainable Economic Development. Dordrecht, the Neth.: Kluwer: 57-69.

Levin, A., Lin, C. and Chu, C. (2002). "Unit Root Tests in Panel Fata: Asymptotic and Ginite-sample Properties." Journal of Econometrics 108: 1-24.

Mak, J. (2004). Tourism and the Economy: Understanding the Economics of Tourism. University of Hawaii Press, Honolulu, HI.

Maloney, W. \& Montes Rojas, G. (2005). "How Elastic are Sea, Sand and Sun? Dynamic Panel Estimates of the Demand for Tourism." Applied Economics Letters, 12 (5): 277280.

Mangion, M. L., Durbarry, R. \& Sinclair, M. T. (2005). "Tourism Competitiveness: Price and Quality." Tourism Economics, 11 (1): 45-68.

Mazanec, J. A., Wober, K. \& Zins, A. H. (2007). “Tourism Destination Competitiveness: From Definition to Explanation.” Journal of Travel Research, 46 (1): 86-95.

Mihalic, T. (2000). "Environmental Management of a Tourist Destination: A Factor of Tourism Competitiveness." Tourism Management, 21 (1): 65-78.

Moore, W. \& Whitehall, P. (2005). "The Tourism Life Cycle and Regime Switching Models.” Annals of Tourism, 32 (1): 112-126. 
Nowak, J., Sahli, M. \& Sgro, P. (2003). “Tourism, Trade and Domestic Welfare.” Pacific Economic Review, 8 (3): 245-258.

Oh, C.O (2005). "The Contribution of Tourism Development to Economic Growth in the Korean Economy." Tourism Management, 26: 39-44.

Papatheodorou, A. \& Song, H. (2005). "International Tourism Forecasts: Time-series Analysis of World and Regional Data." Tourism Economics, 11 (1): 11-23.

Porter, M. E. (1990). The Competitive Advantage of Nations. Free Press, New York, NY.

Ritchie, J. \& Crouch, G.(2003). The Competitive Destination, a Sustainable Tourism Perspective. Wallingford: Cabi Publishing.

Sahli, M. (2006). Tourism Destination Specialization. In International Handbook on the Economics of Tourism, edited by Dwyer L. and Forsyth P. Edward Elgar Edition, pp. 434-463.

Sequeira, N.T. \& Nunes, M.P. (2008). "Does Tourism Influence Economic Growth? A Panel Data Approach." Applied Economics, 40 (18): 2431-2441.

Shan, J. \& Wilson, K. (2001). "Causality Between Trade and Tourism: Empirical Evidence from China." Applied Economics Letters, 8 (4): 279-283.

Shareef, R. (2004). Country Risk Ratings of Small Island Tourism Economies, FEEM Working Paper No.25, Milan.

Sinclair, M.T. \& Stabler, M. (1997). The Economics of Tourism. Routledge, London, UK.

Song, H. \& Witt, S.F. (2000). Tourism Demand Modeling and Forecasting: Modern Econometric Techniques. Amsterdam: Pergamon.

Smeral, E. (2003). “A Structural View of Tourism Growth”. Tourism Economics, 9(1): 77-93.

Vanhove, N. (2005). The Economics of Tourism Destinations. Butterworth-Heinemann, Oxford, UK.

Wignaraja, Lezama and Joiner, 2004. Small States in Transition, From Vulnerability to Competitiveness. The Commonwealth Secretariat, London, UK.

World Bank (2000). Toward a Caribbean Vision 2020. CGCED, Washington DC.

World Bank (2005). A Time to Choose, Caribbean Development in the $21^{\text {st }}$ Century, Washington DC. 
Wooldridge, J.M. (2002). Econometric Analysis of Cross-Section and Panel Data. The MIT Press, Cambridge.

Zhang, J. \& Jensen, C. (2007). "Comparative Advantage: Explaining Tourism Flows." Annals of Tourism Research, 34 (1): 223-243. 
Figure 1. Level of competition within the Caribbean Region, 1988-2008.

Figure 1a. Competition Total Caribbean

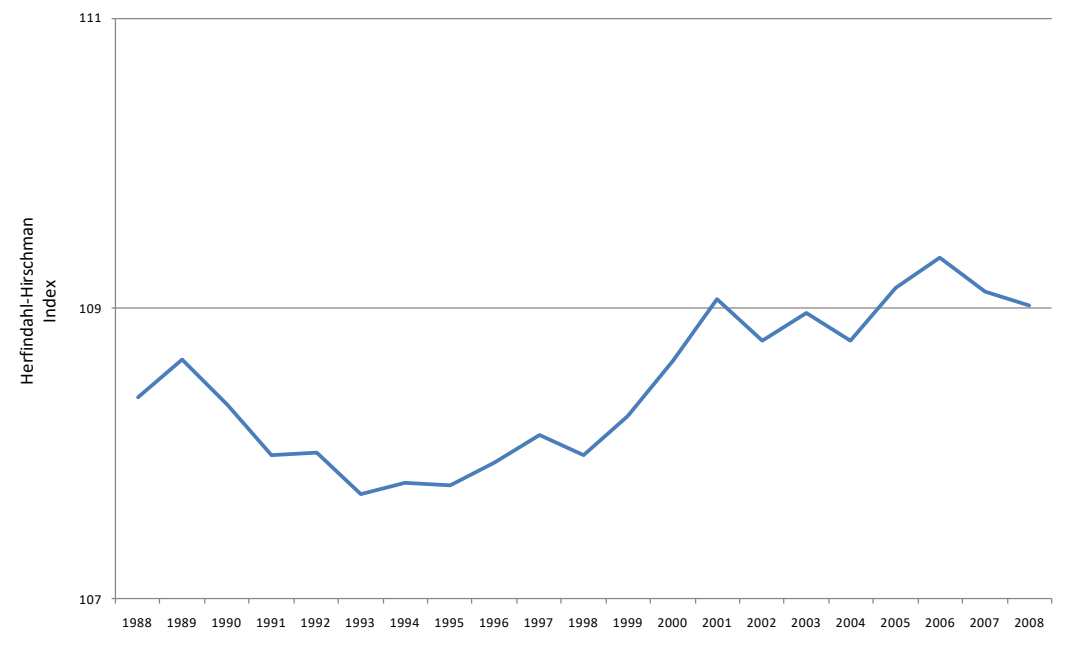

Year
Figure 1b. Competition Small Island Destinations within the Caribbean

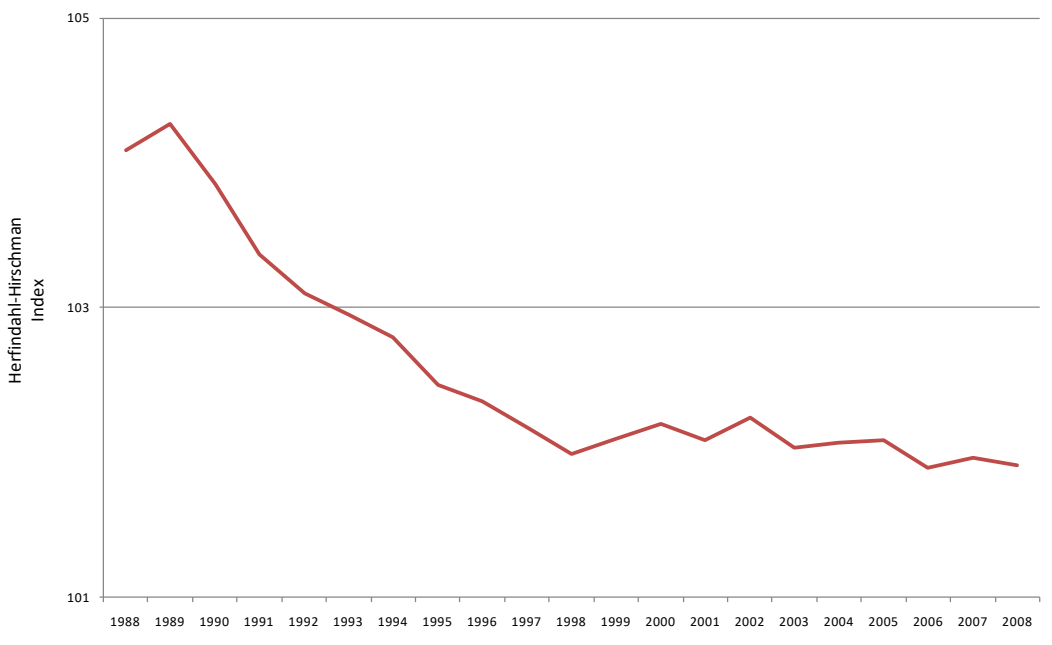

Year 
Table 1. The Tourism Competitiveness Index

\begin{tabular}{|c|c|c|c|c|c|c|c|c|}
\hline Country & $\begin{array}{c}\text { Tourism } \\
\text { Competitiveness } \\
\text { Index }\end{array}$ & Rank & $\begin{array}{c}\text { Tourism } \\
\text { Receipts } \\
\text { per } \\
\text { capita }\end{array}$ & Rank & $\begin{array}{c}\text { Growth } \\
\text { Rate of } \\
\text { Tourism } \\
\text { Receipts }\end{array}$ & Rank & $\begin{array}{c}\text { Tourism } \\
\text { Value } \\
\text { Added } \\
\text { Ratio of } \\
\text { GDP }\end{array}$ & $\begin{array}{c}\text { Rank of } \\
\text { VA }\end{array}$ \\
\hline Aruba & 0.752 & 1 & $\$ 10,960$ & 3 & 0.087 & 3 & 0.680 & 2 \\
\hline British Virgin Islands & 0.751 & 2 & $\$ 19,864$ & 1 & 0.067 & 8 & 0.441 & 8 \\
\hline Anguilla & 0.639 & 3 & $\$ 6,308$ & 7 & 0.084 & 5 & 0.671 & 3 \\
\hline US Virgin Islands & 0.623 & 4 & $\$ 13,573$ & 2 & 0.055 & 11 & 0.559 & 4 \\
\hline Antigua and Barbuda & 0.442 & 5 & $\$ 4,088$ & 8 & 0.035 & 15 & 0.789 & 1 \\
\hline Cayman Islands & 0.428 & 6 & $\$ 7,060$ & 4 & 0.073 & 7 & 0.253 & 13 \\
\hline Bahamas & 0.395 & 7 & $\$ 6,466$ & 6 & 0.038 & 14 & 0.531 & 5 \\
\hline Guadeloupe & 0.394 & 8 & $\$ 553$ & 16 & 0.091 & 1 & 0.317 & 11 \\
\hline Saint Lucia & 0.392 & 9 & $\$ 2,225$ & 10 & 0.059 & 10 & 0.529 & 6 \\
\hline Grenada & 0.357 & 10 & $\$ 645$ & 15 & 0.086 & 4 & 0.276 & 12 \\
\hline Dominica & 0.329 & 11 & $\$ 800$ & 13 & 0.082 & 6 & 0.243 & 14 \\
\hline Saint Kitts and Nevis & 0.318 & 12 & $\$ 2,140$ & 11 & 0.053 & 12 & 0.421 & 9 \\
\hline Barbados & 0.316 & 13 & $\$ 2,638$ & 9 & 0.046 & 13 & 0.457 & 7 \\
\hline St. Vincent \&Grenadines & 0.309 & 14 & $\$ 842$ & 12 & 0.065 & 9 & 0.350 & 10 \\
\hline Martinique & 0.298 & 15 & $\$ 675$ & 14 & 0.09 & 2 & 0.103 & 16 \\
\hline Bermuda & 0.136 & 16 & $\$ 6,550$ & 5 & 0.017 & 16 & 0.130 & 15 \\
\hline
\end{tabular}


Table 2. Panel Unit Root Test

\begin{tabular}{lclll}
\hline \multicolumn{4}{c}{ Levin-Lin-Chu test } \\
\hline & Sample & \multicolumn{1}{c}{ Levels } & $\begin{array}{c}\text { First } \\
\text { Difference }\end{array}$ & $\begin{array}{c}\text { Degree of } \\
\text { Integration }\end{array}$ \\
\hline Value & $1999-2005$ & 4.287 & $-7.534^{*}$ & I (1) \\
Arrival & $1999-2005$ & -0.793 & $-211.803^{*}$ & I (1) \\
Price & $1999-2005$ & $-6.542^{*}$ & $* 25.107^{*}$ & I (0) or I (1) \\
GDP Cap & $1999-2005$ & $-1.490^{*}$ & $-38.241^{*}$ & I (0) or I (1) \\
Room & $1999-2005$ & $-3.978^{*}$ & $-70.142^{*}$ & I $(0)$ or I $(1)$ \\
\hline
\end{tabular}

Notes: The panel comprised of nine destinations in the Caribbean. The table reports the adjusted statistic (t-star) for the Levin-Lin-Chu (2002) test at the 1\% and 10\%

significance level. An $*,(* *)$ indicates rejection of the null hypothesis at the $1 \%$ and $10 \%$ significance level. The test was carried out using STATA 9. 
Table 3. Results of the Fixed Effect Model

Determinants of Competitiveness in Small Island Destinations

\begin{tabular}{lccccc}
\hline \multicolumn{6}{c}{ Dependent Variable $=$ Rate difference in real spending per tourist $(=\mathrm{value})$} \\
\hline \multicolumn{1}{c}{ Variable } & $\begin{array}{c}\text { Short term } \\
\text { Coefficient }\end{array}$ & $\begin{array}{c}\text { Std. } \\
\text { Error }\end{array}$ & $\mathrm{t}$ & $\mathrm{p}>/ \mathrm{t} /$ & $\begin{array}{c}\text { Long term } \\
\text { Coefficient }\end{array}$ \\
\hline Arrivals & -.375 & -.125 & -3.00 & 0.005 & -.503 \\
$\begin{array}{l}\text { Price } \\
\text { Level of Development } \\
\text { technology) }\end{array}$ & .455 & .105 & 4.30 & 0.000 & .611 \\
Level of Investment & .639 & .262 & 2.43 & 0.020 & .857 \\
\hline
\end{tabular}

